\title{
Hybrid epoxy nanocomposites: lightweight materials for structural applications
}

\author{
Sanjeev Kumar Srivastava ${ }^{1,2}$ and Indu Prakash Singh ${ }^{1}$
}

The processing parameters, namely, clay loading, magnetic stirring time and sonication time, were optimized for the dispersion of two types of clay into an epoxy and into chopped strand mat (CSM) glass fiber-based epoxy nanocomposite laminates. A vacuum-assisted resin transfer molding setup was used to fabricate these laminates. Optimizations were performed based on improvements in Young's modulus. The intercalated and exfoliated distributions of clay in the composites were confirmed using $\mathrm{X}$-ray diffraction and transmission electron microscopy. The transmission electron micrographs of optimized specimens showed a well-ordered intercalated structure within the epoxy. Using optimized processing conditions, three layered laminates of CSM, woven roving glass fibers or both were prepared with epoxy and clay for the preparation of new lightweight hybrid epoxy nanocomposites. The tensile, flexural and impact properties of these hybrid nanocomposites were investigated. A combination of the two types of glass fibers produced promising results.

Polymer Journal (2012) 44, 334-339; doi:10.1038/pj.2011.140; published online 18 January 2012

Keywords: clay; epoxy; exfoliation; hybrid epoxy nanocomposites; intercalation

\section{INTRODUCTION}

Epoxies are generally used in structural applications. Epoxy-based plastics provide extraordinary mechanical properties, including good dimensional stability, minimal water absorption, and chemical and corrosion resistance. ${ }^{1}$ Within the past two decades, nanoparticles have been utilized to enhance the mechanical properties of available plastics. $^{2}$ Enhancements have come about in the form of high-specific moduli and increased specific strength. Toyota Research Labs first introduced clay into a Nylon 6 resin for seat belts, and an improvement in the thermomechanical properties ${ }^{3-5}$ was observed. Clays (layered silicates) are commonly used to make polymer nanocomposites; these belong to a structural family known as the 2:1 layered clays or phyllosilicates. Montmorillonite clay consists of several hundreds of individual nanoscale layers held together by electrostatic forces. It is the most commonly used layered silicate ${ }^{6}$ clay. The clay particles exhibit high strength and stiffness along their lengths as compared with glass fibers, ${ }^{7}$ and they have a high aspect ratio, thus providing a large surface area for contact with polymers. ${ }^{8}$ These particles are in the form of platelets that are $0.96 \mathrm{~nm}$ thick and $250 \mathrm{~nm}$ in both length and width. ${ }^{8}$ The homogeneous dispersion of clay into polymers is a challenging task. Previous studies suggest that three forms of structural morphologies may be obtained after dispersion of clay into a polymer, including intercalation, exfoliation and phase-separated structures. ${ }^{9-14}$ Unidirectional glass fiber epoxy laminates are used for structural applications because of their high-specific strength and stiffness in preferred directions. However, in a number of applications, multiaxial loading is encountered. Composite laminates with appropriate combinations of chopped strand mat (CSM-C) and woven roving (WR-W) are found to give superior results. ${ }^{15}$

Therefore, there is a need to optimize the processing parameters for the homogeneous dispersion of clay into epoxies and to study the scope of combining two types of glass fibers in the development of hybrid epoxy nanocomposites.

\section{EXPERIMENTAL PROCEDURE}

Materials

The CSM (M6-450) and WR (M-630) glass fibers used in this study were procured from Dhingra Plastics, New Delhi, India (Figure 1). CSM consists of randomly distributed short $(\sim 50 \mathrm{~mm})$ fibers. CSM ranging in length from 3.2 to $12.7 \mathrm{~mm}$ were used for making the composites. WR is a coarse fabric that has continuous roving woven in two mutually perpendicular directions. Difunctional diglycidyl ether of bisphenol-A epoxy resin (BI-53R) and a hardener (PH-861, Aliphatic polyamine) from Resinova Chemie Ltd. (Kanpur, India), were used as the matrix. The hardener ( $10.0 \mathrm{wt} \%$ of epoxy) was added to epoxy, and a styrene monomer ( $1.0 \mathrm{wt} \%$ of epoxy) was used to thin down the epoxy mixture to make it easier to pour into the mold. Montmorillonite nanoclays modified with methyl tallow bis-2-hydroxyethyl quaternary ammonium chloride, Cloisite 30B (cation exchange capacity (CEC) -90 meq per $100 \mathrm{~g}$ clay) and Cloisite 15A (CEC -125 meq per $100 \mathrm{~g}$ clay), were procured from Southern Clay Products (Gonzales, TX, USA).

${ }^{1}$ Instrument Design Development Centre, Indian Institute of Technology, New Delhi, India and ${ }^{2}$ Vishveshwarya Institute of Engineering and Technology, Dadri, Gautam Budh Nagar, Uttar Pradesh, India

Correspondence: Dr SK Srivastava, Instrument Design Development Centre, Indian Institute of Technology, New Delhi 110016, India.

E-mail: sansrivastava28@yahoo.co.in

Received 2 July 2011; revised 23 October 2011; accepted 14 November 2011; published online 18 January 2012 

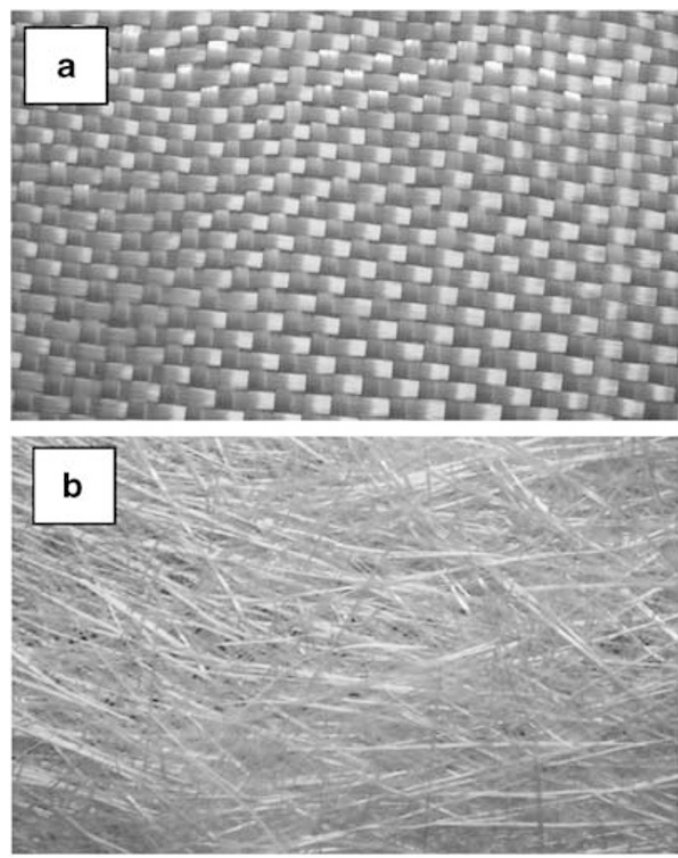

Figure 1 Types of glass fiber used: (a) woven roving and (b) chopped strand mat. A full color version of this figure is available at Polymer Journal online.

\section{Preparation of glass fiber-based epoxy nanocomposites for the optimization of processing parameters}

Clays in different weight percentages (0.0, 0.5, 1.0 and $2.0 \mathrm{wt} \%)$ are mixed with the epoxy and acetone. Acetone was used to dilute the epoxy and clay solution. ${ }^{16}$ The ratio of clay to acetone is $1 \mathrm{~g}$ to $15 \mathrm{ml}$. It was mixed using a magnetic stirrer $(60,120$ and $180 \mathrm{~min})$ for a fixed period of time before sonication $(15,30$ and $45 \mathrm{~min})$. For the homogeneous dispersion of clay into the epoxy matrix, the clay loading $(\mathrm{CL})$ was optimized for the fixed parameters of magnetic stirring time (MST) and sonication time. Then, the CL and sonication time were held constant in order to optimize the MST. Finally, the CL and MST were kept fixed to optimize the sonication time. These optimizations were performed based on the improvement in Young's modulus relative to the pure epoxy composite.

In each step, after it is magnetically stirred, the mixture is heated at $100{ }^{\circ} \mathrm{C}$ for at least $15 \mathrm{~min}$ to remove the acetone before sonication. After sonication, the mixture is cooled for $15-20 \mathrm{~min}$ to room temperature, and then $10.0 \mathrm{wt} \%$ of the hardener and $1.0 \mathrm{wt} \%$ by weight of styrene are added to the mixture. It is then poured into a vacuum-assisted resin transfer molding (Figure 2) containing three layers of CSM glass fibers as reinforcement. CSM was chosen for optimization because it produces isotropic laminates. The curing time is 10-12 h. Mixing using a mechanical stirrer provides kinetic energy to the liquid polymer, causing it to dissociate into tiny molecules. The particle size reduction and dispersion of the nanoclay is achieved because of high-frequency vibrations from ultrasonic mixing.

\section{Preparation of hybrid epoxy nanocomposites}

Three layers of glass fiber-based epoxy nanocomposites (GFENs) are prepared with different combinations of CSM and WR, denoted CCC, WWW, WCW, CCW, CWC and WWC, using optimized processing parameters for both types of clay in the epoxy matrix as described in section 'Preparation of glass fiber-based epoxy nanocomposites for the optimization of processing parameters,' to observe the effects of the laminate configuration. In addition, the hybrid epoxy nanocomposites with Cloisite 30B are only prepared for flexural and impact testing.

\section{Specimen preparation and mechanical testing}

Tensile tests are generally performed on flat specimens. Commonly used specimens for tensile tests are the dog bone and the straight side configurations with end tabs. ${ }^{17}$ The dog bone-type tensile samples take time to machine, so the

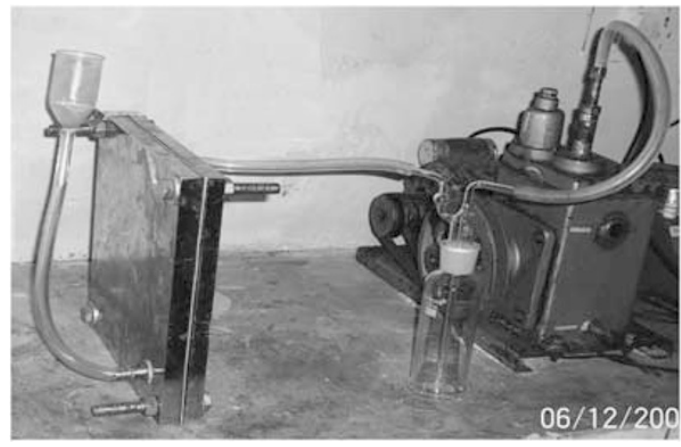

Figure 2 Vacuum-assisted resin transfer molding (VARTM) setup. A full color version of this figure is available at Polymer Journal online.

straight-sided samples are permitted by the American Society for Testing and Materials (ASTM). Any nicks or burrs along the edge of the specimens will concentrate stress, which can cause the sample to yield and fracture prematurely. ${ }^{18}$ Straight-sided tensile specimens ${ }^{19-20}$ of $63.5 \pm 2.5 \times 9.53 \pm 0.375 \times$ $3.5 \pm 0.2 \mathrm{~mm}$, similar to ASTM D638-08 (type v), are used in this study. Tension tests are conducted on an Instron Universal Testing Machine (Instron Co. Ltd. Norwood, MA, USA, type 5582) in accordance with ASTM D638 standards, ${ }^{21}$ with a nominal crosshead speed of $2.0 \mathrm{~mm} \mathrm{~min}^{-1}$. Young's modulus is measured from this test.

Flexural tests are also conducted on an Instron Universal Testing Machine (type 5582) as per ASTM D790 standards, ${ }^{22}$ with a nominal crosshead speed of $5.0 \mathrm{~mm} \mathrm{~min}^{-1}$. A support span to depth ratio of $16: 1$ is used for this test. The specimen is loaded until rupture occurs on the outer surface of the test specimen or until a maximum strain of $5 \%$ is reached, whichever occurs first. The flexural modulus is determined from this test.

An izod impact test is carried out on notched specimens $63.5 \pm 2.0 \times$ $12.7 \pm 0.20 \times 3.5 \pm 0.2 \mathrm{~mm}$, as per ASTM D256 standards. ${ }^{23}$ The velocity of the striker at the moment of impact is approximately $3.5 \mathrm{~m} \mathrm{~s}^{-1}$. Impact energy is recorded from this test.

All the above tests are repeated on at least five specimens. The mean of the five tests and their estimated standard deviations are presented, up to three significant digits. ${ }^{21}$

\section{Physical characterization of epoxy nanocomposites}

$\mathrm{X}$-ray diffraction (XRD) and transmission electron microscopy (TEM) were performed on representative specimens in order to observe the distribution of clay in the epoxy. Some representative data and micrographs are presented.

XRD pattern. XRD analysis of the samples was performed using a wide-angle Phillips XRD spectrometer (PANalytical B.V., Almelo, The Netherlands). An accelerating voltage of $45 \mathrm{kV}$ and current of $30 \mathrm{~mA}$ were applied using $\mathrm{Cu} \mathrm{K} \alpha$ radiation $(\lambda=0.154 \mathrm{~nm})$. A $2 \theta$ scan range from $0^{\circ}$ to $10^{\circ}$ was taken. The value of the observed angle $2 \theta$ was converted to the interlayer spacing $(d)$ of the clay using Bragg's relationship, $n \lambda=2 d \operatorname{Sin} \theta$, where $\lambda$ is the wavelength of the incident X-rays, $\theta$ is the angle of incidence and $n$ is an integer.

Transmission electron microscopy. Ultra-thin sections $(<100 \mathrm{~nm})$ of samples were cut using an ultra microtome (EM Ultracut UC6, Leica Microsystems GmbH, Wetzlar, Germany) equipped with a glass knife. The sections were supported on copper grids (200 mesh) procured from Electron Microcopy Sciences, Hatfield, PA, USA. The micrographs of the specimens were taken using a TEM (Phillips Model CM-12 electron microscope) to observe the morphological effects of optimization parameters.

\section{RESULTS AND DISCUSSION}

Improvement in Young's modulus by inclusion of Cloisite 15A and Cloisite 30B

Table 1 shows the effect of different types of clay on Young's modulus for the epoxy matrix. The pure epoxy and epoxy nanocomposite (with $0.5 \mathrm{wt} \%$ of clay) laminates are prepared after magnetic stirring for 
Table 1 Improvement in Young's modulus by inclusion of Cloisite 15A and Cloisite 30B

\begin{tabular}{lc}
\hline Material & Young's modulus (GPa) \\
\hline Pure epoxy & $0.701( \pm 0.143)$ \\
Epoxy+Cloisite 15A composite & $0.872( \pm 0.036)$ \\
Epoxy+Cloisite 30B composite & $0.999( \pm 0.076)$ \\
\hline
\end{tabular}

$120 \mathrm{~min}$ and sonication for $30 \mathrm{~min}$. The addition of both types of clay enhances the modulus of the epoxy matrix. These results also confirm the possibility of improvements in the mechanical properties of glass fiber epoxy composites by incorporating clay as filler. These changes may be due to the proper dispersion of clay into the epoxy.

\section{Tensile and flexural properties of GFEN based on Cloisite 15A and Cloisite 30B}

The processing methods (stirring and sonication) also played an important role in determining the structure and properties of the epoxy nanocomposites in addition to CL. The effect of the MST on the mechanical properties was observed. The mechanical properties were improved in comparison to the pure epoxy composites by dissociation of the polymer into tiny molecules and penetration into the galleries of the clay layers. The study on the effect of sonication showed that the mechanical properties were mostly improved, similar to those reported elsewhere. ${ }^{24}$ Young's modulus and the flexural modulus of the GFENs are given in Tables 2 and 3, for both clays. Specimens prepared with CL of $2.0 \mathrm{wt} \%$, with $120 \mathrm{~min}$ of magnetic stirring and 30 min of sonication, show a maximum improvement in Young's modulus for both types of clay. This is due to the intercalation of the epoxy resin between layers in the nanoclay, as supported by the TEM images. The flexural modulus is also improved with the inclusion of both Cloisite 15A and Cloisite 30B. A CL of $2.0 \mathrm{wt} \%$ and with magnetic stirring for $120 \mathrm{~min}$ and sonication for $30 \mathrm{~min}$ are found to be optimal for both Cloisite 15A and Cloisite 30B. The improved modulus can be directly ascribed to a stiffening effect from the clay fillers, as the inclusion of clay provides a higher modulus than the neat epoxy. It is observed that the processing parameters that give XRD peaks provide better Young's modulus than those not showing any diffraction peaks, providing a better flexural modulus relative to the pure epoxy composites. It should be noted that if sonication continues for a prolonged period of time, the mechanical properties of the resultant nanocomposites may be degraded. For example, sonication for $45 \mathrm{~min}$ was found to degrade Young's modulus and the flexural modulus for both types of clay.

\section{Comparison of the effects of different types of clay on GFEN}

Both types of clay, Cloisite 15A and Cloisite 30B, improve the tensile and flexural moduli (Figures $3 \mathrm{a}$ and $\mathrm{b}$ ). Kornmann et al. ${ }^{25}$ showed that there is a marginal improvement of $6 \%$ in the flexural modulus of epoxy composites after dispersion of $2.0 \mathrm{wt} \%$ clay particles, and similar behavior was also observed by Haque et al. ${ }^{26}$ On the basis of the improvements in Young's modulus and the flexural modulus, it can be concluded that Cloisite 30B is more compatible with the epoxy matrix than Cloisite 15A; Cloisite 30B improves Young's modulus by $147 \%$ and the flexural modulus by $133 \%$. This may be result from a maximum enhancement in the interlayer spacing of Cloisite $30 \mathrm{~B}$ powder in comparison with Cloisite 15A, as is further supported in Table 4. In contrast, the morphologies of both of the clay nanocomposites are related to the $\mathrm{CEC}$ of the original clay. The nanocomposites made from Cloisite 30B (CEC -90 meq per 100 g clay) generally show
Table 2 Optimization of process parameters (Cloisite 15A-based GFEN)

\begin{tabular}{lcc}
\hline Type of specimen & Young's modulus (GPa) & Flexural modulus (GPa) \\
\hline CL-0, MST-60, ST-30 & $0.79( \pm 0.312)$ & $3.30( \pm 1.135)$ \\
CL-0.5, MST-60, ST-30 & $1.18( \pm 0.438)$ & $6.98( \pm 0.302)$ \\
CL-1, MST-60, ST-30 & $1.92( \pm 0.215)$ & $6.93( \pm 0.232)$ \\
CL-2, MST-60, ST-30 & $1.93( \pm 0.064)$ & $5.35( \pm 0.736)$ \\
CL-2, MST-120, ST-30 & $2.12( \pm 0.131)$ & $6.50( \pm 0.328)$ \\
CL-2, MST-180, ST-30 & $2.00( \pm 0.121)$ & $6.75( \pm 0.284)$ \\
CL-2, MST-120, ST-15 & $1.91( \pm 0.104)$ & $5.73( \pm 0.325)$ \\
CL-2, MST-120, ST-45 & $2.06( \pm 0.073)$ & $6.75( \pm 0.179)$ \\
\hline
\end{tabular}

Abbreviations: CL, clay loading; GFEN, glass fiber-based epoxy nanocomposite; MST, magnetic stirring time; ST, sonication time.

Table 3 Optimization of process parameters (Cloisite 30B-based GFEN)

\begin{tabular}{lcc}
\hline Type of specimen & Young's modulus (GPa) & Flexural modulus (GPa) \\
\hline CL-0, MST-60, ST-30 & $0.79( \pm 0.312)$ & $3.30( \pm 1.135)$ \\
CL-0.5, MST-60, ST-30 & $1.69( \pm 0.188)$ & $7.70( \pm 0.283)$ \\
CL-1, MST-60, ST-30 & $1.91( \pm 0.317)$ & $6.72( \pm 0.207)$ \\
CL-2, MST-60, ST-30 & $1.96( \pm 0.208)$ & $7.41( \pm 0.564)$ \\
CL-2, MST-120, ST-30 & $2.30( \pm 0.135)$ & $7.00( \pm 0.745)$ \\
CL-2, MST-180, ST-30 & $2.02( \pm 0.364)$ & $8.08( \pm 1.284)$ \\
CL-2, MST-120, ST-15 & $2.01( \pm 0.118)$ & $5.49( \pm 0.249)$ \\
CL-2, MST-120, ST-45 & $2.11( \pm 0.192)$ & $6.49( \pm 0.163)$ \\
\hline
\end{tabular}

Abbreviations: CL, clay loading; GFEN, glass fiber-based epoxy nanocomposite; MST, magnetic stirring time; ST, sonication time.

a greater interlayer spacing than those made from Cloisite 15A (CEC -125 meq per $100 \mathrm{~g}$ clay), similar to results reported elsewhere. ${ }^{27}$

\section{X-ray diffraction analysis}

Wide-angle XRD studies are conducted on pure clays and epoxy composites with varying processing parameters. These are designated A1, B1, C1, D1 and E1 for Cloisite 15A, and A2, B2, C2, D2, E2 and F2 for Cloisite 30B, as shown in Table 4 and Figure 4 . The Cloisite 15A (A1) and Cloisite 30B (A2) powder have an interlayer spacing of $1.18 \mathrm{~nm}$ and $0.92 \mathrm{~nm}$ at diffraction angles $(2 \theta)$ of $7.44^{\circ}$ and $9.59^{\circ}$, respectively. A shift in the diffraction peak due to enhancement in the interlayer spacing is observed after stirring and sonication of Cloisite $15 \mathrm{~A}$ and Cloisite 30B into the epoxy matrix (Figures $4 \mathrm{a}$ and $\mathrm{b}$ ). The enhancement in the interlayer spacing is observed for both types of clay, as shown in Table 4. From Table 4, it is observed that $2.0 \mathrm{wt} \%$ of CL with $60 \mathrm{~min}$ of magnetic stirring and $30 \mathrm{~min}$ of sonication gives a maximum interlayer spacing value of $1.51 \mathrm{~nm}$ at a diffraction angle (20) of $5.84^{\circ}$. This specimen also gives the maximum Young's modulus (Table 3) on the basis of CLs. Specimens (C1 and F2) not showing any diffraction peaks, but providing better flexural moduli (Table 4), indicate the possibility of an exfoliation phenomena. Specimens based on the optimized processing parameters for both types of clay (CL-2.0 wt\%, MST-120 min and sonication time $30 \mathrm{~min}$ ) show enhanced interlayer spacing, suggesting the possibility of intercalation phenomena. These are confirmed with TEM.

\section{TEM characterization of epoxy nanocomposites}

TEM allows a qualitative understanding of the internal structure and spatial distribution of various phases and defects in structures through 

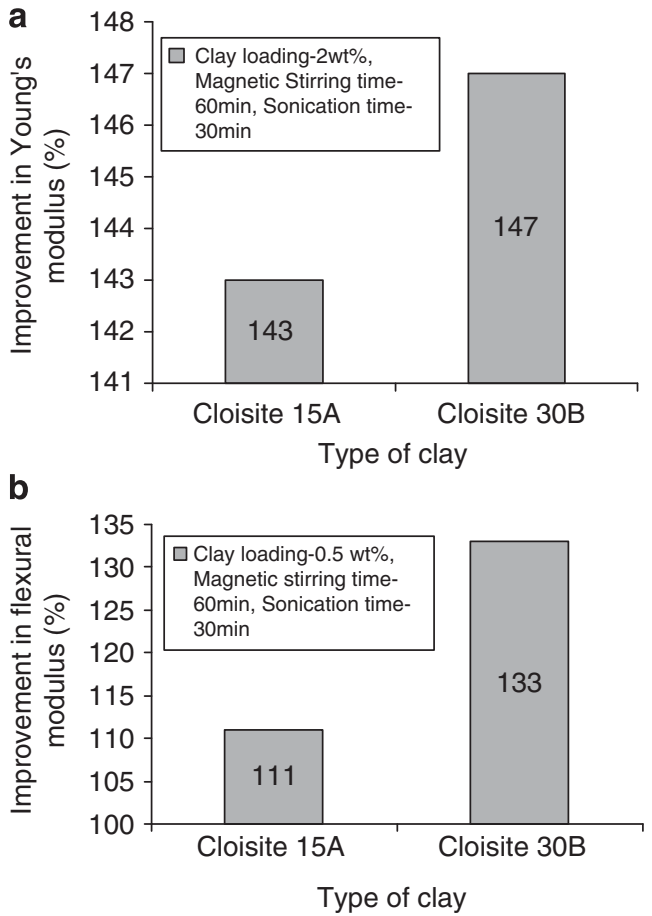

Figure 3 (a). Tensile properties of glass fiber-based epoxy nanocomposite (GFEN) for both types of clay. (b) Flexural properties of GFEN for both types of clay. A full color version of this figure is available at Polymer Journal online.

Table 4 Interlayer spacing (d) for epoxy nanocomposites based on (a) Cloisite 15A and (b) Cloisite 30B

\begin{tabular}{|c|c|c|c|c|}
\hline Symbol & $\begin{array}{l}\text { Type of specimen (CL (wt\%), } \\
M S T \text { (min) and ST (min)) }\end{array}$ & $\begin{array}{c}\text { Angle } \\
(2 \theta)\end{array}$ & $\begin{array}{c}\text { Interlayer } \\
\text { spacing } \\
(n m)\end{array}$ & $\begin{array}{c}\text { Young's } \\
\text { modulus } \\
\text { (GPa) }\end{array}$ \\
\hline \multicolumn{5}{|l|}{ (a) } \\
\hline A1 & Pure Cloisite $15 \mathrm{~A}$ & 7.44 & 1.18 & - \\
\hline B1 & $2.0 \mathrm{wt} \%, 120 \mathrm{~min}, 30 \mathrm{~min}$ & 6.15 & 1.43 & 2.12 \\
\hline C1 & $1.0 \mathrm{wt} \%, 60 \mathrm{~min}, 30 \mathrm{~min}$ & - & No peak & $1.92^{\mathrm{a}}$ \\
\hline D1 & 0.5 wt $\%, 60 \mathrm{~min}, 30 \mathrm{~min}$ & 5.96 & 1.48 & 1.18 \\
\hline E1 & $2.0 \mathrm{wt} \%, 60 \mathrm{~min}, 30 \mathrm{~min}$ & 5.84 & 1.51 & 1.93 \\
\hline \multicolumn{5}{|l|}{ (b) } \\
\hline A2 & Pure Cloisite 30B & 9.59 & 0.92 & - \\
\hline B2 & $2.0 \mathrm{Wt} \%, 120 \mathrm{~min}, 30 \mathrm{~min}$ & 5.70 & 1.54 & 2.30 \\
\hline $\mathrm{C} 2$ & $1.0 \mathrm{Wt} \%, 60 \mathrm{~min}, 30 \mathrm{~min}$ & 5.94 & 1.48 & 1.91 \\
\hline D2 & $0.5 \mathrm{Wt} \%, 60 \mathrm{~min}, 30 \mathrm{~min}$ & 6.06 & 1.45 & 1.69 \\
\hline E2 & $2.0 \mathrm{Wt} \%, 60 \mathrm{~min}, 30 \mathrm{~min}$ & 5.93 & 1.48 & 1.96 \\
\hline $\mathrm{F} 2$ & $2.0 \mathrm{Wt} \%, 180 \mathrm{~min}, 30 \mathrm{~min}$ & - & No peak & $2.02^{\mathrm{a}}$ \\
\hline
\end{tabular}

Abbreviations: $\mathrm{CL}$, clay loading; MST, magnetic stirring time; ST, sonication time. aProvides maximum flexural modulus.

direct visualization. Thin films used in the TEM studies for Cloisite 15A- and Cloisite 30B-based specimens of GFEN were prepared by ultramicrotomy, with thicknesses in the range of $60-80 \mathrm{~nm}$. Montmorillonite clays consist of several sheets ( $\sim 1 \mathrm{~nm}$ thick) stacked face to face. An agglomeration of these stacks leads to micron-sized particles. The formation of a nanocomposite involves the fragmenta-
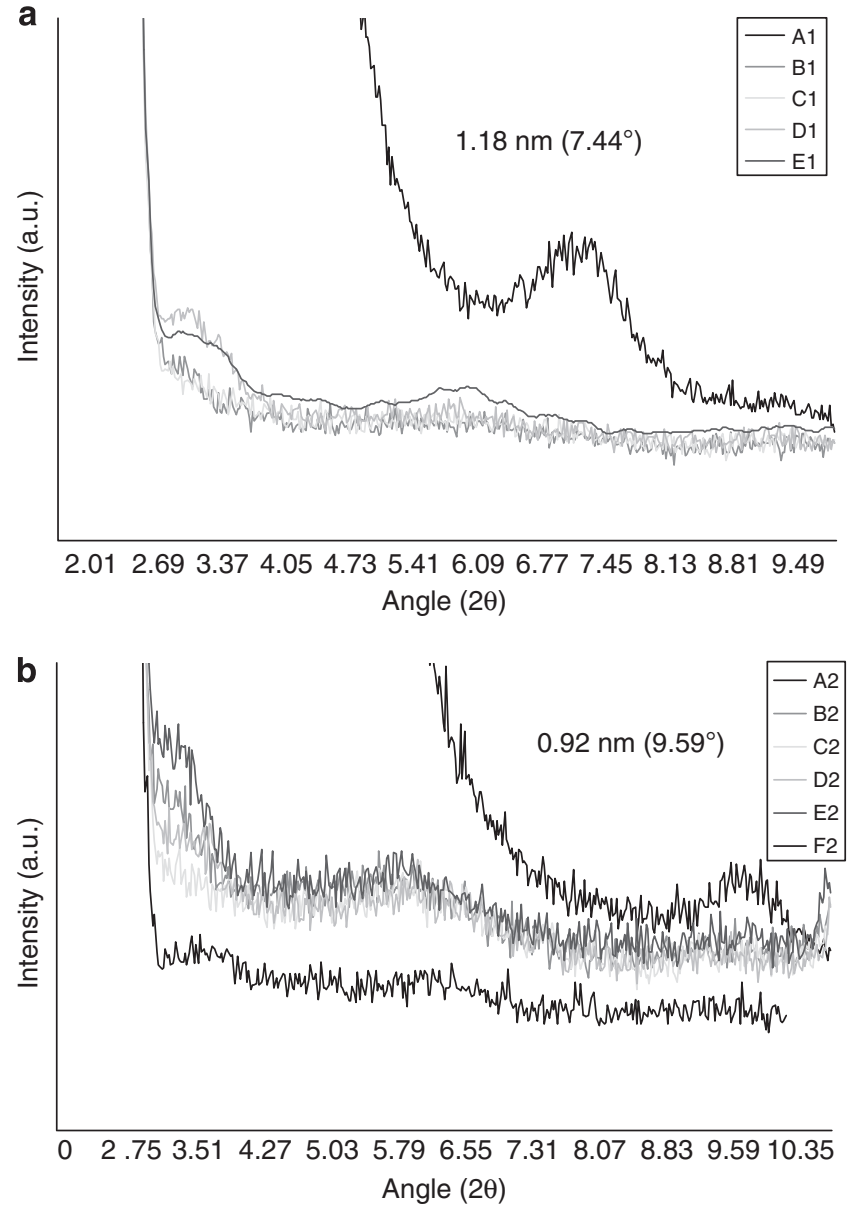

Figure 4 (a) X-ray diffraction pattern of Cloisite 15A-based epoxy nanocomposites. (b) X-ray diffraction pattern of Cloisite 30B-based epoxy nanocomposites. A full color version of this figure is available at Polymer Journal online.

tion and dispersion of the agglomerated stacks of the sheets, followed by the swelling of the gallery spacing between the sheets by the epoxy resin. Figures 5 and 6 show TEM micrographs of the epoxy with Cloisite 15 and Cloisite 30B, respectively. The dark regions indicate the clay layers, and the bright region indicates the polymer matrix. Figure $5 \mathrm{a}$ shows the intercalated nanocomposite structure with an increase in the interlayer spacing. This figure also shows the voids that are formed during the curing process. Figure 6 a shows that the clay is well dispersed and separates into layers (intercalated morphology). The separation of these layers indicates that the epoxy material has penetrated into the gallery region of the clay. Figure $6 \mathrm{~b}$ shows the exfoliation phenomena of the Cloisite 30B into the epoxy matrix. This specimen does not show a diffraction peak in the XRD spectra. Figures $5 \mathrm{~b}$ and $6 \mathrm{c}$ show the presence of well-separated clay layers in the matrix epoxy cured at room temperature.

\section{Mechanical properties of hybrid epoxy nanocomposites}

Hybrid epoxy nanocomposites are prepared using clays such as Cloisite $15 \mathrm{~A}$ and Cloisite 30B. Figure 7 represents the ratio of the Young's modulus of the composite $\left(E_{\mathrm{c}}\right)$ to the Young's modulus of the epoxy matrix $\left(E_{\mathrm{m}}\right)$ for different configurations of the hybrid epoxy nanocomposites. Configuration CCC exhibits a smaller Young's modulus ratio than the other types of laminates. CCW with Cloisite 30B 

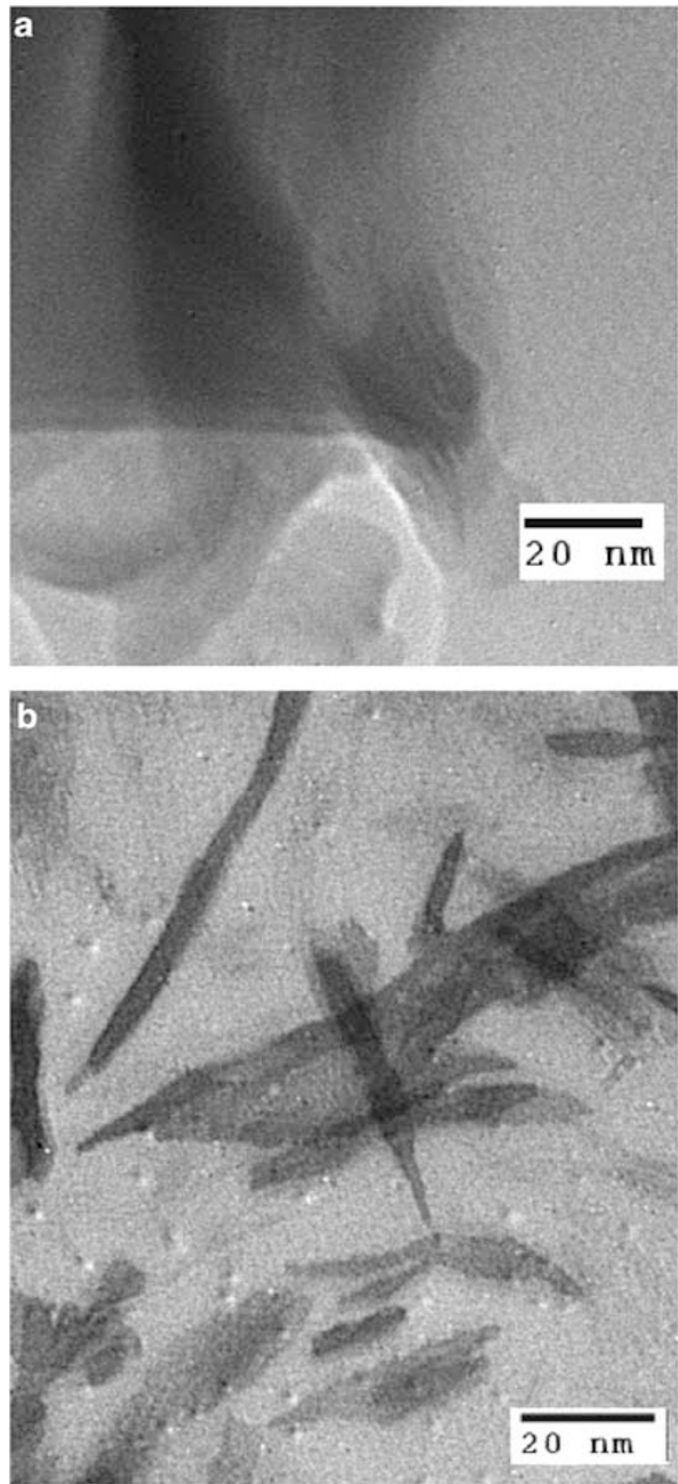

Figure 5 (a) Transmission electron microscopy (TEM) of epoxy nanocomposites (Cloisite 15A) showing good intercalation morphology (clay loading (CL)-2.0 wt\%, magnetic stirring time (MST)-120 min and sonication time (ST)-30 min). (b) TEM of epoxy nanocomposites (Cloisite 15A) showing good exfoliated morphology (CL-1.0 wt\%, MST-60 min and ST-30 min).

and WWC with Cloisite 15A show a higher modulus ratio compared to the other laminates. CCC and WCW configurations from both types of CL show approximately the same modulus ratio.

The flexural loadings are applied on specimens CCC, CWC, WWC, WCW, CCW and WWW. The specimens with asymmetric constitutions (WWC and CCW) are loaded such that the first layer is in the upper position. For example, in the case of WWC, the loading direction is from the WR layer (W) to the CSM layer (C). From Table 5, it can be seen that WCW and WWC provide better flexural moduli compared with CWC and CCW. WWW shows the minimal flexural modulus.

Results of izod impact tests on the hybrid epoxy nanocomposites are also given in Table 5. For all the hybrid nanocomposites, the impact energy lies between the CCC and WWW configurations. Configuration WWC shows the maximum impact energy of all the
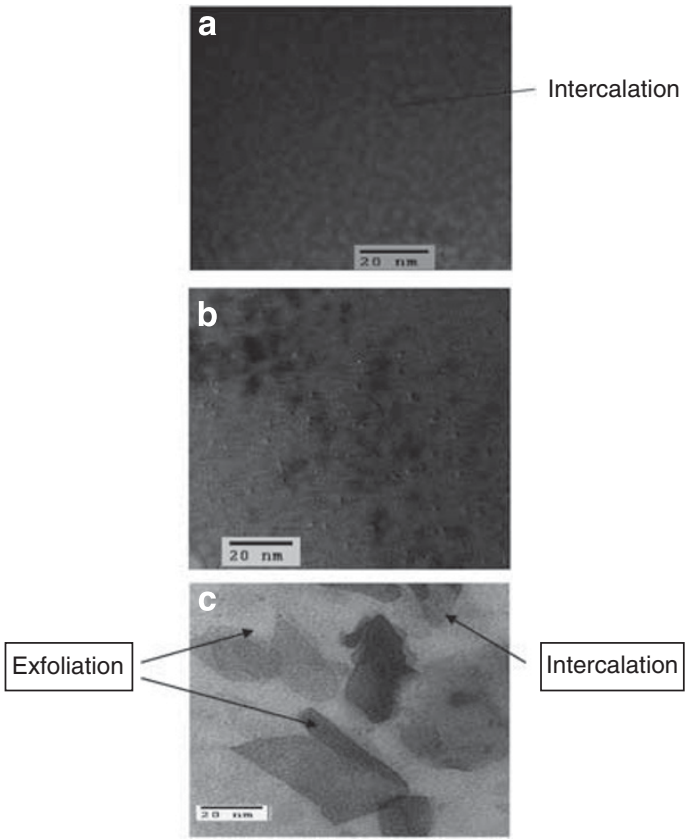

Figure 6 (a) Transmission electron microscopy (TEM) of epoxy nanocomposites (Cloisite 30B) showing good intercalation morphology (CL-2.0 wt\%, MST- $120 \mathrm{~min}$ and ST-30 min). (b) TEM of epoxy nanocomposites (Cloisite 30B) showing good exfoliation morphology (CL-2.0 wt\%, MST$180 \mathrm{~min}$ and ST-30 min). (c) TEM of epoxy nanocomposites (Cloisite 30B) showing partial exfoliation and intercalation morphology (CL-2.0 wt\%, MST$180 \mathrm{~min}$ and ST-30 min).

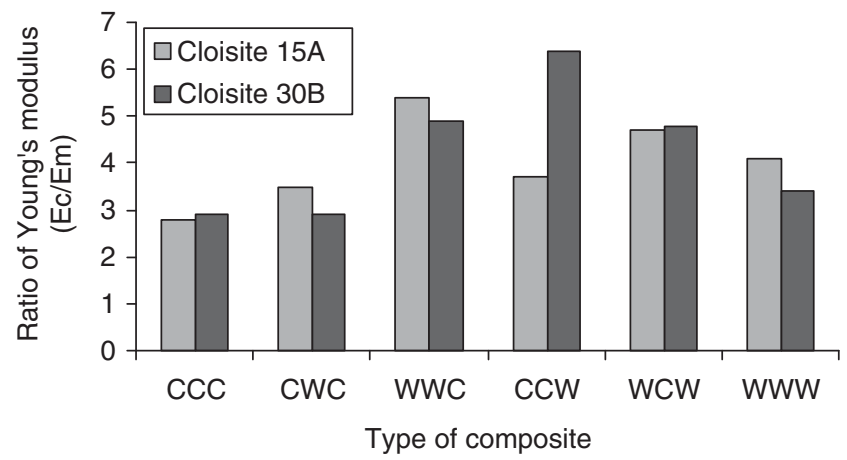

Figure 7 Ratio of Young's modulus of composite $\left(E_{\mathrm{c}}\right)$ to Young's modulus of matrix $\left(E_{\mathrm{m}}\right)$. A full color version of this figure is available at Polymer Journal online.

Table 5 Flexural modulus and impact energy of hybrid epoxy nanocomposites

\begin{tabular}{lcc}
\hline Type of composite & Flexural modulus (GPa) & Impact energy $(\mathrm{J})$ \\
\hline CCC & $7.00( \pm 0.745)$ & 2.63 \\
CWC & $4.72( \pm 0.415)$ & 3.61 \\
WWC & $8.02( \pm 0.726)$ & 4.27 \\
WCW & $11.6( \pm 0.472)$ & 3.96 \\
CCW & $4.74( \pm 0.637)$ & 3.76 \\
WWW & $3.76( \pm 0.404)$ & 4.94 \\
\hline
\end{tabular}

Abbreviations: C, chopped strand mat; W, woven roving. 
other combinations of CSM and WR. Configuration WWW shows the maximum impact energy of all the combinations. Improvements in impact energy may be due to the predominance of WR glass fibers.

\section{CONCLUSIONS}

Increases in Young's modulus in glass fiber epoxy composites are obtained by the inclusion of two types of clay in the epoxy, as fabricated using a vacuum-assisted resin transfer molding setup. Improvements in the mechanical properties are attributed to the proper impregnation of fibers into the clay containing resin. A homogenous dispersion may be achieved using a combination of processing parameters, such as a CL of $2.0 \mathrm{wt} \%$ with magnetic stirring for $120 \mathrm{~min}$ and sonication for $30 \mathrm{~min}$ for both types of clay. The Cloisite 30B samples show better compatibility with the epoxy matrix than the Cloisite 15A nanocomposites. The Cloisite 30B nanocomposites showed greater improvements in Young's modulus, enhanced interlayer spacing and an intercalated morphology than the Cloisite 15A-based nanocomposites. Although some combinations of nanocomposites seemed to be exfoliated by XRD, with plaques that were optically clear, a mixture of partially intercalated and exfoliated layers also existed. The resin with clays shows distinctive peaks even at lower organoclay concentrations, and specimens showing no XRD peaks indicate an exfoliated phenomena and show maximum flexural moduli. Further, hybrid nanocomposites show promising results owing to their improvement in mechanical properties. Hybrid combinations, WCW and WWC, are observed to give better flexural moduli and impact energies. In conclusion, different combinations of CSM and WR showed significant mechanical improvements, either in terms of the tensile properties, flexural properties and impact properties or in terms of a combination of two of these properties at the expense of a third. Further insight into the exfoliation phenomena of nanocomposites that showed maximum flexural moduli may be gained by studying their structural morphology.

1 Vishwanath, B., Verma, A. P., Rao, C.V.S.K. \& Gupta, R. K. Effect of different matrices on wear characteristics of glass woven roving/polymer composites. Composites 24, 347-353 (1993).

2 Maniar, K. K. Polymeric nanocomposites: a review. Polym. Plastics Technol. Eng. 43, 427-443 (2004).

3 Usuki, A., Kojima, Y., Kawasumi, M., Okada, A., Fukushima, Y., Kurauchi, T. \& Kamigaito, O. Synthesis of nylon 6-clay hybrid. J. Mater. Res. 8, 1179-1184 (1993).
4 Usuki, A., Kawasumi, M., Kojima, Y., Okada, A., Kurauchi, T. \& Kamigaito, O. Swelling behavior of montmorillonite cation exchanged for $\omega$-amino acids by caprolactam. J. Mater. Res. 8, 1174-1178 (1993).

5 Kojima, Y., Usuki, A., Kawasumi, M., Okada, A., Fukushima, Y., Kurauchi, T. \& Kamigaito, O. Mechanical properties of nylon 6-clay hybrid. J. Mater. Res. 8, 1185-1189 (1993).

6 Giannelis, E. P. Polymer-layered silicate nanocomposites: synthesis, properties and applications. Appl. Organo. Chem. 12, 675-680 (1998).

7 Luo, J. J. \& Daniel, I. M. Characterization and modeling of mechanical behavior of polymer/clay nanocomposites. Compos. Sci. Technol. 63, 1607-1616 (2003).

8 Hackman, I. \& Hollaway, L. Proceedings of the International Symposium on Bond Behaviour of FRP in Structures (BBFS 2005) 525-530 (2005).

9 Ray, S. S., Yamada, K., Okamoto, M., Ogami, A. \& Ueda, K. New polylactide/layered silicate nanocomposites. 3. High-performance biodegradable materials. Chem. Mater. 15, 1456-1465 (2003).

10 Maiti, P., Yamada, K., Okamoto, M., Ueda, K. \& Okamoto, K. New polylactide/layered silicate nanocomposites: role of organoclays. Chem. Mater. 14, 4654-4661 (2002).

11 Ray, S. S., Okamoto, K. \& Okamoto, M. Structure property relationship in biodegradable poly(butylenes succinate)/layered silicate nanocomposites. Macromol. 36, 2355-2367 (2003).

12 Ray, S. S., Yamada, K., Okamoto, M. \& Ueda, K. Polylactide-layered silicate nanocomposite: a novel biodegradable material. Nano. Lett. 2, 1093-1096 (2002).

13 Alexandre, M. \& Dubois, P. Polymer-layered silicate nanocomposites: preparation, properties and uses of new class of materials. Mater Sci. Eng. 28, 1-63 (2000).

14 LeBaron, P. C., Wang, Z. \& Pinnavaia, T. J. Polymer-layered silicate nanocomposites: an overview. Appl. Clay Sci. 15, 11-29 (1999).

15 Mariatti, M. \& Chum, P. K. Effect of laminate configuration on the properties of glass fiber-reinforced plastics (GFRPs) mixed composites. J. Reinf. Plas. Compos. 24, 1713-1721 (2005).

16 Liu, W., Hoa, S. V. \& Pugh, M. Morphology and performance of epoxy nanocomposites modified with organoclay and rubber. Polym. Eng. Sci. 44, 1178-1186 (2004).

17 Mahapatra, S. S. \& Chaturvedi, V. Modeling and analysis of abrasive wear performance of composites using Taguchi approach. Int. J. Eng. Sci. Technol. 1, 123-135 (2009).

18 Technical Tidbits. Published by Brush Wellman 3, 1-2 (2001).

19 Khondker, O. A., Ishiaku, U. S., Nakai, A. \& Hamada, H. Fabrication mechanical properties of unidirectional jute/PP composites using jute yarns by film stacking method. J. Polym. Environ. 13, 115-126 (2005).

20 Satapathy, A. \& Patnaik, A. Analysis of dry sliding wear behavior of red mud filled polyester composites using the Taguchi Method. J. Reinf. Plast. Compos. (2005) http:// dx.doi.org/10.1177/071684408092453.

21 ASTM D638. Standard test method for tensile properties of plastics (2008).

22 ASTM D 790 M-84. Standard methods for flexural properties of unreinforced and reinforced plastics and electrical insulating materials.

23 ASTM D256. Standard test methods for determining the Izod pendulum impact resistance of plastics (2006).

24 Lam, C. K., Lau, K. T., Cheung, H. Y. \& Ling, H. Y. Effect of ultrasound sonication in nanoclay clusters of nanoclay/epoxy composites. Mater. Lett. 59, 1369-1372 (2005).

25 Kornmann, X., Rees, M., Thomann, Y., Barbezat, M. \& Thomann, R. Epoxy-layered clay nanocomposites as a matrix in glass fiber-reinforced composites. Compos. Sci. Technol. 65, 2259-2268 (2005).

26 Haque, A., Hussain, F., Derrick, D. \& Shamsuzzoha, A. M. S2-glass/epoxy polymer nanocomposites: manufacturing, structures thermal and mechanical properties. J. Compos. Mater. 37, 1821-1837 (2003).

27 Chen, C. \& Curliss, D. Preparation, characterization, and nanostructural evolution of epoxy nanocomposites. J. App. Polym. Sci. 90, 2276-2287 (2003). 